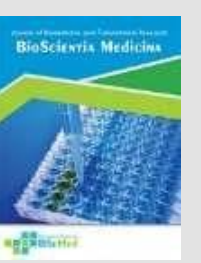

Bioscientia Medicina: Journal of Biomedicine \& Translational Research

Journal Homepage: $\underline{w w w . b i o s c m e d . c o m}$

\title{
Etiology, Diagnosis, and Treatment of Leukorrhea
}

\section{Damai Trilisnawati ${ }^{*}$, Izazi Hari Purwoko, Mutia Devi ${ }^{1}$, Suroso Adi Nugroho ${ }^{1}$, Fitriani ${ }^{1}$, Theresia L. $^{\text {The }}$ Toruan ${ }^{1}$}

${ }^{1}$ Department of Dermatology and Venereology, Faculty of Medicine, Universitas Sriwijaya, Palembang, Indonesia

\section{A R T I C L E I N F O Keywords: \\ Diagnosis \\ Etiology \\ Leukorrhea \\ Management \\ *Corresponding author: \\ Damai Trilisnawati \\ E-mail address: dr.damai@yahoo.com}

All authors have reviewed and approved the final version of the manuscript.

\begin{abstract}
A B S T R A C T
The most frequently reported complaints in the urogenital organ system is leukorrhea, also known as fluor albus. Leukorrhea is a discharge secreted from the genital organs, mostly occur in female. Leukorrhea has a significant incidence rate and varies according to many factors such as hormone and infection. Leukorrhea can be physiological in female, but when excess discharge is accompanied by other characteristics, the leukorrhea is considered pathological. This genital discharge also occurs in male for pathological reasons, mainly caused by infection. Several pathogenic infections, whether transmitted through secual contact or not, are the etiology of complaints of leukorrhea. Some specific pathogens will cause different symptoms in the two sex groups. To make a diagnosis, it is important for the examiner to carry out a detailed and coherent history, especially regarding sexual contact and a history of risky sexual behavior. Although some infections are asymptomatic, complications may occur if infections are not treated properly as early as possible. The management of leukorrhea is based on an examination and treatment algorithm with syndromic approach.
\end{abstract}

https://doi.org/10.32539/bsm.v5i6.323

\section{Introduction}

Leukorrhea, also known as fluor albus is a body discharge that is secreted from the genital organs excessively [1]. In women, it may be physiological or pathological. Physiological leukorrhea occur according to menstruation process, usually transparent to whitish coloured, and odorless. On the other hand, pathological leukorrhea is usually yellowish/greenish/greyish, smells fishy/foul, foul, the usually in large amount and causes complaints such as itching, redness (erythema), edema, burning sensation in the genitals, pain during sexual intercourse (dyspareunia) or pain during sexual intercourse. urination (dysuria) [1,2]. In male, urethral discharge, either plenty or little is an indication inflammation response and shows to be pathological [3].
A study conducted by Bai in 2015 shows that urethral discharge becomes the most complained symptom consulted to a doctor. The highest incidence is found in the 21-30 years old age group. Pathological leukorrhea indicates vaginitis or cervicitis. Three most common vaginal infection in pathological leukorrhea includes bacterial vaginosis (BV), candidiasis vulvovaginalis (VVC) and trichomoniasis, whereas cervical infection includes gonorrhea and chlamydiosis [4]. Rodrigues et al. reported that in 2017, 785 male patients $(98.1 \%)$ visit the sexually transmitted disease (STD) clinic due to urethral discharge. Common causes include Neisseria gonorrhoeae ( $N$. gonorrhoeae) 42,7\% non-gonococcal urethritis (NGU) 39,3\%, Chlamydia trachomatis (C. trachomatis) $10,7 \%$, and $7,3 \%$ chlamydia and gonococcal co-infection [5].

Clinical manifestations of leukorrhea and urethral 
discharge doesn't lead to mortality. However, it cause increased morbidity due to irritation and itch that leads to discomfort in sexual activity. Diagnosis is made through obtaining patient's history and laboratory exams. The treatment is given in accordance with the causative pathogen/s [7, 8]. Untreated physiological leukorrhea may progress to pathological leukorrhea with the risk of reproductive health disorder such as infertility [1].

In this review, we will discuss about the etiology, diagnosis, and treatment of leukorrhea in female and male patients with the aim to achieve deeper understanding about clinical manifestations of leukorrhea, thus diagnosis and treatment can be done and given.

\section{Epidemiology}

Pathological leukorrhea becomes the most common etiology in reproductive aged women [9]. A study by Venupagol in 2017 reported BV as the most common pathological cause $(27 \%)$, followed by trichomoniasis (25\%), VVC (22\%), co-infection (Candida and BV) (3\%), and non-specific infection (23\%) [10]. Gheddar et al. in 2010 reported that in Lebanon, 39\% pregnant women is infected by Candida. Most infections are caused by Non-Candida albicans Candida (NCAC) as much as 58\%, mainly C. glabrata and C. krusei [11]. Nayak et al. conducted a study in 2017 and found that two third of men had gonococcal urethritis and from 100 patients, $68 \%$ complained urethral discharge accompanied with dysuria. Most common pathological etiology are $N$. gonorrhoeae (45\%), C. trachomatis (13\%), and $T$. vaginalis in two patients [3].

\section{Anatomy of female and male genital organ}

The anatomy of female genital organ is classified into internal and external organs. External genital organ includes the mons pubis, labia major, labia minor, clitoris, vestibule, Bartholin gland and perineum. Internal genital organ consists of vagina, uterus, fallopian tube and ovarium (Fig 1a.). The vagina is a fibromuscular cavity consisting of anterior, posterior, and two lateral walls. In prepuberty and post-menopause the vaginal epithelium becomes thinner. The vaginal epithelium is composed of stratified squamous epithelium, consisting of basal, intermediate, and superficial cornified cells. Intermediate and superficial cells contain a lot of glycogen which is influenced by sex hormones. Superficial cells become exfoliative when inflammation or neoplasia is present. The amount of physiological vaginal discharge is very small only to moisten the wall surfaces. In some conditions the discharge will increase, such as in the middle or several days before menstruation, pregnancy, and during sexual intercourse. The discharges originate from the cervical glands, uterus, vaginal epithelial transudation, and Bartholin's glands) [1]. The male urethra is divided into three segments, namely the prostate, incarcerated, and anterior urethra (Figure 1b) [12].

\section{Etiopatogenesis}

There are several factors affecting physiological leukorrhea, namely age (prepubertal, reproductive, post-menopausal), hormones (hormonal contraception, hormonal cycle changes, pregnancy), and local factors such as menstruation, post-partum, malignancy, semen, and personal hygiene habits $[1,13]$. Hormonal effects on normal vaginal flora are important for differentiating physiological and pathological discharges. During reproductive age, vaginal bacteria are dominated by lactobacilli in the form of gram positive, facultative anaerobic Lactobacillus acidophilus but the absence of Lactobacillus does not mean that it causes abnormalities in the vagina [13]. A study conducted by Ravel et al. (2011) reported that $73 \%$ of vaginal normal flora is dominated by $\geq 1$ Lactobacillus species, Lactobacillus crispatus ( $L$. crispatus) in $26,2 \%$ cases, followed by $L$. gasseri, $L$. inners, dan L. jensenii [14]. The production of lactic acid and hydrogen peroxide $\left(\mathrm{H}_{2} \mathrm{O}_{2}\right)$ can maintain acidity levels $(\mathrm{pH} \leq 4.5$ or range $3.8-4,4)$ vaginal ecosystem. Production of $\mathrm{H}_{2} \mathrm{O}_{2}$ by Lactobacilli is a normal nonspecific vaginal antimicrobial defense mechanism. There are differences in the composition of normal bacteria in menopausal women. Estrogen is known to 
play an important role in glycogen deposits and maturation of vaginal epithelium [13]. Hummelen, et al. in 2011 observed that the microbiota in menopausal women was dominated by $L$. iners and $L$. vaginalis. The number of Lactobacillus varies in menopausal women affecting the degree of vaginal dryness. Diversity of bacteria in the vagina causes vaginal dryness, this is inversely related to the number of Lactobacillus [15]. Post-menopausal women found anaerobic vaginal flora 7.8 times higher than the flora of $L$. crispatus. Meanwhile, normal vaginal flora in peri-menopausal women is dominated by L. gasseri or L. jensenii [13].

The level of vaginal acidity at reproductive age is 4.0-4.5. In pre-menarche or post-menopausal women, leukorrhea is found in high $\mathrm{pH}$ due to decreased level of estrogen and glycogen metabolism. Changes in $\mathrm{pH}$ can also differentiate the causes of vaginal infections. The increase in $\mathrm{pH}$ in non-infectious conditions can be due to the presence of blood during menstruation, semen from sexual intercourse, cervical discharges, or broken amniotic fluid. The function of local innate immunity in the female genital tract (FGT) has an important role in vaginal dysbiosis. Discharges and the integrity of the vaginal epithelium is one of body's defence against cervicovaginal pathogens prior to hostorganism interactions or vaginal infection. There is involvement of innate and adaptive immunity in FGT. Estradiol and progesterone play a major role in the activation of the immune system with the formation consisting of chemokines and cytokines. In the activation against microbes, antigen-presenting cells (APC) such as epithelial cells and dendritic cells process antigens from pathogens and present them to $\mathrm{T}$ cells to induce activation and elaboration of cytokines, chemokines, and antibodies. The role of the innate immune system in FGT is not only in the recognition of pathogen-associated molecular patterns (PAMPs) but also in several receptors such as T-like receptors which are expressed on epithelial cells, macrophages, dendritic cells, neutrophils, and natural killer cells causing the formation of immune cells and production of antimicrobial factors [13].

\section{Pathological leukorrhea}

Pathological leukorrhea is commonly caused by cervical and vaginal abnormality that can be noninfection or infection [9].

\section{Female patients}

\section{Non Infection}

Non-infection disorders that cause vaginitis include foreign bodies, vulvar vestibulitis, and allergic vaginitis. A foreign object in the vagina causes inflammation, which results in an unpleasant odor and excess exudate. The most common foreign bodies that cause vaginitis are toilet paper and tampons. Vestibulitis is caused by contact of acidic vaginal discharges with vestibular tissue causing dyspareunia and a burning sensation. Genital hygiene and contraceptive products are the most common etiologies of non-infectious vaginitis that cause allergic contact dermatitis and irritant contact dermatitis [8,9]. Meanwhile, noninfectious cervical disorders are cervical ectopy, chronic cervicitis, mucous polyps, and ectropion.

\section{Infection}

\section{Cervical infection}

Neiserria gonorrhoeae and C. trachomatis are the most common causes of cervical infections (cervicitis). Cervicitis is often asymptomatic, but in some women it is accompanied by complaints of vaginal discharge and intermenstrual vaginal bleeding (after sexual intercourse) [9].

\section{a) Gonorrhea}

In women, the pathogenesis of $N$. gonorrhoeae infection was studied using a fallopian tube organ culture model. The pathogen undergoes pinocytosis by epithelial cells and then bacteria that are actively dividing move from the surface of the mucosal layer to the intraepithelial space. Significant fallopian tube damage in some cases of gonococcal salpingitis suggests a process of invasion, colonization, and infection. Neiserria gonorrhoeae is capable of producing at least one toxin that acts on the tissue or triggers an immune response causing damage to the host cell 
$[16,17]$

\section{b) Chlamydiosis}

Chlamydia is an STI disease caused by $C$. trachomatis bacteria which generally attacks the cervix. Chlamydia trachomatis usually infects the mucosa of columnar epithelial cells and replicates in host cells causing cell death. C. trachomatis invasion and replication induces an immune and inflammatory response in the host. There are several immune responses that occur in the body due to infection with the pathogen $\mathrm{C}$. trachomatis, seen from the number of circulating antibodies and other cell-mediated responses. Chlamydia trachomatis has a protective immune mechanism causing the acute phase of the disease to be self-limited, improving, and gradually become persistent to chronic mild-degree infections $[17,18]$.

\section{Vaginal infection}

Bacterial vaginosis, VVC, and trichomoniasis are the most common conditions causing vaginal infections (vaginitis) $[2,8,17]$. Table 1 describes the characteristics of differences in pathological vaginal leukorrhea [8].

\section{a) Bacterial vaginosis (BV)}

Bacterial vaginosis is the most common asymptomatic vaginal flora disorder, $[8,17]$ due to the change in normal vaginal flora (Lactobacillus) to a predominantly mixed bacteria consisting of Gardnerella vaginalis (G. vaginalis), Mycoplasma hominis (M. hominis) and several other anaerobic bacteria. Most of the research into the pathogenesis of BV has focused on changes in the microbial ecosystem in the vagina. Lactobacilli in the vagina function to inhibit the growth of G. vaginalis, M. hominis, and anaerobic gram-negative bacteria replicating in vitro by producing $\mathrm{H} 2 \mathrm{O} 2$. Various types of bacteria play a role in the pathogenesis of $\mathrm{BV}$ which are thought to produce amines through the activity of the microbial decarboxylase enzyme which causes vaginal discharge to smell fishy. women, and smokers. Douching and poor hygiene of the genital organs can disrupt the normal flora of the vagina, causing recurrent BV $[6,19]$.

\section{b) Vulvovaginal candidiasis}

Vulvovaginal candidiasis causes discomfort in the genital organs, decreased sexual productivity and pleasure, and psychological problems. As many as $75 \%$ of women of reproductive age have at least one episode and $40-45 \%$ two episodes of VVC. Candida infections are most commonly caused by Candida albicans (C. albicans), which is the normal vaginal flora of reproductive age, but can cause $90 \%$ of cases of vaginitis [6 ]. Candida passes into the vaginal lumen and secretes in the vagina through the perianal area. Candida colonization is non-commensal and is always pathological to the host cell. Some women have been found to have C. albicans in the vagina, although it does not always cause symptoms. The growth and replication of fungi in the reproductive tract is influenced by several predisposing factors, namely (a) pregnancy, which physiologically increases vaginal discharges containing glycogen. Glycogen is a good carbon source for C. albicans organisms; (b) use of oral estrogen contraceptives, was found to increase vaginal colonization of fungi; (c) diabetes mellitus, making women more susceptible to C. galbrata infection; (d) ingestion of intravaginal or systemic antibiotics which can eliminate normal microbial flora as an important protective agent in the vagina; and (e) HIV patients [17]. Vulvovaginal candidiasis was classified into uncomplicated and complicated based on frequency, symptoms, microbiological examination, and response to treatment (Table 2). Complicated vulvovaginal candidiasis was defined as VVC recurring $\geq 4$ times per year [2].

\section{c) Trichomoniasis}

Trichomoniasis is the most common non-viral STI caused by $T$. vaginalis protozoa. Approximately 5 million US women are infected each year. Trichomonas vaginalis can penetrate the mucosal layer and have access to the epithelial cells underneath so that it can infect the urogenital tract. The pathogen will attach to the epithelial cells and trigger the host cell's immune response. Pathogenicity factors of T. vaginalis affect the ability of host cell invasion, including the production of cytotoxic proteolytic enzymes and adhesin protein (AP) 
to the cell surface, which causes parasite-induced cytopathic effects (CPE). Macromolecules in the human body can coat the surface of parasite cells so that the parasites can survive in vivo and carry out metabolism. Trichomonas vaginalis also has the ability to perform phagocytosis. T. vaginalis infection is easily transmitted sexually and has a risk of contracting the human immunodeficiency virus (HIV) through increased vaginal discharge of CD4 + cells, which are the target cells for the HIV virus [2, 6, 17].

\section{Male patients}

Male patients who have a history of urethral discharge, dysuria, or itching at the end of the urethra at a young age are at risk of developing urethritis. The main etiology of urethral discharge in male is $\mathrm{N}$. gonorrhoeae and C. trachomatis. However, T. vaginalis and M. genitalium have also been reported as the cause of urethral discharge. Other pathogens involved in NGU includes Ureaplasma, Tricomonas, and herpes simplex virus (HSV) with recurrent meatal inflammation and oral sex history in MSM. Based on etiology, urethral discharge in men can be divided into two classifications, which are gonococcal and nongonococcal. According to the location, it can be divided into local and systemic. Local infection includes salpingitis, epididymitis, bartolin abscess, lymphangitis, penile edema, periurethral abscess, and prostatitis meanwhile systemic infections include urethritis, cervicitis, proctitis, pharyngitis, bartolinitis, and conjunctivitis (Figure 2) [16].

\section{Gonococcal}

New cases of Neisseria gonorrhoeae are usually symptomatic,but may also have minimal or asymptomatic symptoms. Mucous membranes lined with non-cornified columnar or cuboidal epithelial cells are susceptible to gonococcal bacterial infection. Infection begins with the attachment of $\mathrm{N}$. gonorrhoeae to mucosal cells mediated by pili, opa, and several other surface proteins. Gonococcal bacterial endotoxin in the form of lipooligosaccharides interferes with cilia motility and plays a role in the destruction of other ciliated cells around it. Progressive damage to mucosal cells and invasion of the submucosal layer is followed by an immune response of polymorphonuclear cells $(\mathrm{PMN})$, resulting in microabscesses and exudation of purulent material into the lumen of infected organs $[3,16]$.

\section{Non-gonococcal}

The most common etiologies of non-gonococcal urethritis (NGU) are C. trachomatis (15-40\%) and $M$. genitalium (15-20\%) while the etiologies of T. vaginalis, herpes simplex virus, Epstein Barr virus, and adenovirus are rarely found in NGU [3].

\section{a. Chlamydiasis}

C. trachomatis infection in males can cause urethritis, epididymitis, prostatitis, proctitis, or reactive arthritis usually accompanied by conjunctivitis, pharyngitis, and lymphogranuloma venereum (LGV). Chlamydia trachomatis is an anaerobic Gram-negative bacteria, an obligate intracellular pathogen that replicates in eukaryotic cells [3]. The pathogenesis of Chlamydia infection consists of several stages, namely the initial attachment of Chlamydia infectious particles, known as elementary body (EB); entrance into the cell; reticulate particle morphological changes occur with intracellular growth and active replication; causing morphological changes of reticulate particles to EB; and release of infectious particles. The process is associated with the attachment and penetration of $\mathrm{EB}$ to susceptible host cells. This pathogen becomes a parasite, especially in squamocolumnar-columnar epithelial cells $[3,18]$.

\section{b. Mycoplasmosis}

Four of the 13 Mycoplasma species that can colonize the human body are found in the genital tract, namely M. hominis, M. genitalium, Ureaplasma parvum (U. parvum), and $U$. urealitycum. In adults, colonization of Mycoplasma and Ureaplasma generally occurs after sexual contact. Research on chimpanzees infected with Mycoplasma shows the development of urethritis as a 
large part of the research object, the discovery of Mycoplasma up to 18 weeks after inoculation and the response of host humoral antibodies [3].

\section{c. Trichomoniasis}

Trichomonas vaginalis is a significant pathogen causing a wide variety of genitourinary syndromes including urethritis. Male patients with urethral discharges and confirmed $\mathrm{T}$. vaginalis infection usually have a history of sexual intercourse with women with trichomoniasis. The $\mathrm{T}$. vaginalis parasite penetrates the mucosal layer to the epithelial cells and adheres, causing tissue damage and inflammation. This parasite produces many proteolytic enzymes which are involved in cytotoxicity, hemolysis, decreased immune response and attachment. Molecules derived from host cells such as a1-antitrypsin, a2-macroglobulin, fibronectin, lactoferrin, and other iron-binding or containing proteins as well as lipids and lipoproteins play a role in coating the surface of parasite cells and helping cells in vivo [20].

\section{Clinical Manifestation}

\section{a. Clinical manifestation of leukorrhea in female}

Patients with leukorrhea usually complain smelly vaginal discharge with vaginal itchiness. The discharge is usually a thin liquid but sometimes may be thick and sticky. The color of pathological leukorrhea may be whitish, greyish-white, yellowish, greenish, reddish, dark colored or rustic. It may be accompanied with other symptoms such as excessive amount of discharge, itchiness, burnt sensation [1,2]. There are several other clinical manifestations accompanying complaints of leukorrhea due to infection in the vagina such as thigh and leg muscle pain, burning sensation when urinating, foul odor, itching or pain in the infected area, anorexia, constipation, and fatigue. Meanwhile, cervical leukorrhea is usually accompanied with low back pain [9].

There are several differences in clinical manifestations of leukorrhea in women based on the causative agent. In BV, the discharge smells strong, usually fishy, and appears on the introitus of the vagina, especially after sexual intercourse [5]. Fig 3. shows a thin layer of greyish white discharge on the vaginal wall accompanied with fishy vulva without signs of inflammation in the vulva or vagina $[17,19]$.

Meanwhile, in VVC there are signs of inflammation that are more prominent in the vulva such as pruritus, discomfort, dyspareunia, dysuria, and there is excess body discharge with varying consistency. The body is usually lumpy, white and odorless with signs of inflammation such as erythema, vaginal fissure or edema and irritation / excoriation of the vulva due to epithelial invasion by pathogens (Figure 4). With VVC there is no increase in vaginal $\mathrm{pH}$. There may also be severe VVC characterized by extensive vulvar erythema, edema, excoriation, and fissures [10].

Trichomoniasis infection is $50-75 \%$ asymptomatic. As many as $30 \%$ only cause symptoms after 6 months of infection. The amount of vaginal discharge is large, yellow or green in color, has a strong odor, and is frothy (Figure 5a). There is hemorrhagic petechiae on the vaginal wall called "strawberry cervix" (Figure 5b) [20]. The most frequent and similar clinical manifestations are found in VVC and trichomoniasis, namely back pain and lower abdominal pain followed by vulvar pruritus, fishy discharge and burning sensation when urinating, and there are signs of inflammation $[9,10]$.

Gonococcal infection and chlamydiosis usually present with leukorrhea and purulent or mucopurulent discharge in the endocervix $[9,16]$.

\section{b. Clinical manifestations of gonorrhea in male}

Urethral discharge in males is commonly accompanied by an inflammatory manifestation of the urethra known as urethritis. The man diagnosed with gonococcal urethritis complained of profuse and spontaneous drainage from the urethra (Figure 7). Urethral discharges due to gonococcal infection have a yellowish color but can also be greenish in color, described as purulent discharge. The incubation period for gonococcal bacteria is shorter, ranging from 2-6 days after exposure. Gonococcal infection without complications, present with symptoms of acute anterior urethritis and may be accompanied by dysuria. 
Discharge is predominantly purulent and profuse within 24 hours of onset. Dysuria is only felt after urethral discharges first appear. Urethral meatal edema and erythema usually accompany gonococcal urethritis. The 25\% range of urethral discharges is not purulent and in small amounts, so it is difficult to distinguish from NGU $[10,16]$.

Genital organ infections caused by C. trachomatis and $\mathrm{N}$. gonorrhoeae have similar clinical manifestations because both infect the columnar or transitional epithelial tissue in the urethra and extend to the epididymis. Both can cause extensive subepithelial inflammation, epithelial ulceration and wound formation. It is difficult to distinguish between infected and uninfected patients based on symptoms. Patients generally come to the clinic after an incubation period of 7-21 days complaining of dysuria and mild moderate degree of urethral discharge, white or clear in color. In some cases, C. trachomatis can cause epididymitis symptoms [10].

T. vaginalis infection as a cause of non-chlamydial NGU in men, but symptoms are not as specific as in women. The incubation period ranges from 3-9 days. Men diagnosed with trichomoniasis are generally asymptomatic. Symptoms may include less urethral discharge and less purulent than gonococcal infection. The clinical manifestations of $\mathrm{T}$. vaginalis infection are prostatitis and epididymitis. Persistent trichomoniasis is usually accompanied by an anterior urethral stricture, although there is no clear causal relationship. Research on a married couple in Cuba who visited an infertility clinic showed that $T$. vaginalis parasites and their proteins could inhibit sperm motility. Men with trichomoniasis have a greater tendency to experience impaired sperm motility and morphology accompanied by increased viscosity of semen and the presence of debris particles [10].

\section{Diagnosis}

\section{a. Diagnosis of leukorrhea in female patients}

Vulvovaginitis symptoms can be diagnosed through basic diagnostic procedure such as anamnesis, physical examination and other supportive examination which includes vaginal $\mathrm{pH}$ examination, whiff/KOH test, and microscopic wet preparation test. Microbiologic examination is only performed if there is a recurrent or chronic persistent infection [6,8-9].

Common complains would be leukorrhea that is accompanied with malodorous, itchiness, burning sensation, spotting and dyspareunia [6]. Increased amount of discharge, abnormal odor, consistency or color $[8,10]$. History of sexual activity including number of sexual partner, partner's sex, frequency of sexual intercourse, technique, history of STD in patient and partner. Lower abdominal pain indicates ascending infection [6].

Perform an inspection of the external genitalia and perianal area to observe signs of ski changes such as inflammation, ulceration, scratch marks, and lumps. In abnormal condition, leukorrhea may be found on the vulva. Inspect inguinal lymph node enlargement to rule out the differential diagnosis of primary genital herpes. Examination using a speculum is essential to identify inflammation, ulcers, strictures, neoplasia, and vaginal and cervical discharges. The amount, consistency, and location of vaginal discharge must be assessed. Discharges are taken with a cotton swab from the vaginal wall avoiding contamination of the cervical mucus as it will cause a false positive. The whitish color should be considered compared to the white color on cotton swabs. The acidity level of the vagina should be determined directly by rubbing a cotton swab containing the specimen onto $\mathrm{pH}$ indicator paper [6].

Supporting examinations that can be carried out are in the form of examination of wet preparations and microbiological examination. The specimen for examination of wet preparations taken by vaginal vaginal discharge is mixed with one drop of saline plus one drop of $10 \% \mathrm{KOH}$ on the slide. Identify the fishy odor after mixing the specimen with $\mathrm{KOH}$. Microscopic examination of saline and $\mathrm{KOH}$ wet preparations aims to detect normal epithelial cells, clue cells, PMN leukocytes, motile trichomonas, or fungal forms, especially fungal hypha and their numbers. The diagnosis of $\mathrm{BV}$ is established if it meets the three criteria of Amsel, namely homogeneous adherent white 
discharges, $\mathrm{pH}$ 4.5, clue cells, and amine odor after discharges are mixed with $10 \% \mathrm{KOH}$. [4] Gram staining of vaginal discharges using the Nugent score is the gold standard for the diagnosis of BV. Scores 0-3 are interpreted as "normal flora", 4-6 "intermediate flora", and 7-10 for VB. [6] Table 3 describes the important microscopic examination of wet preparations performed in patients with complaints of vaginal discharges. Vaginal discharge is allowed to stand for \pm 10 minutes to avoid structural changes. The whiff test (KOH test) was only performed on patients who complained of a fishy odor (amine odor) who showed suspicion of BV [7]. Microscopic examination of wet preparations in trichomoniasis found trichomonads movement, increased leukocyte count, and $\mathrm{pH}>4.5$. Whereas in VVC, spores, hyphae, or yeast buds will be found on the examination of wet preparations [6].

If diagnosis cannot be confirmed through microscopic examination, microbiological examination is indicated. Examination for C. albicans, T. vaginalis culture or gram staining may be necessary to rule out other differential diagnoses [6].

Perform swabs if there are indications for microbiological examination according to the location of the suspected abnormality (vaginitis or cervicitis). Swabs for bacterial culture are taken from the surface of the cervix around the outside of the cervix or from the vagina, swabs for molecular diagnosis of Chlamydia are taken from the cervical canal, and swabs for fungal culture are taken from infected sites in the vagina and vulva. Some of the conditions indicated by microbiological examination are purulent cervicitis (swab originating from the cervical canal), HBV with additional complaints such as lower abdominal pain, suspicion of a fungal infection but negative wet preparation, recurrent chronic mycosis, results of wet preparations found more leukocytes than epithelium or leukocytes> 25 in cervical discharges (magnification 400x). External vulvitis is one indication of microbiological examination. The most common causes were C. albicans followed by Staphylococcus aureus and Streptococcus pyogenes. Microbiological culture examination on $\mathrm{BV}$ will reveal a quantitative and qualitative decrease in Lactobacillus colonies accompanied by an increase in anaerobic bacteria such as G. vaginalis, M. spp., L. sneathia, Megasphaera, and M. hominis. Women with suspected trichomoniasis but no movement of trichomonads on microscopic examination are recommended for microbiological culture.

The diagnostic flow chart for leukorrhea in women based on symptoms using speculum examination and microscopic examination (Fig.8) and using special laboratory examinations (Figure 9) [22]. The goal of the leukorrhea management strategy in women is to systematically treat vaginal infections but the risk of cervical infection is also assessed. If the risk assessment is positive, the patient should be given additional treatment for gonococcal infection and chlamydia. Markers of risk such as symptomatic partner, age <21 years, unmarried, and having had more than one or had new sexual partners in the last 3 months. Once the possibility of cervical infection has been ruled out, subsequent management diagnosis focuses on vaginal infections [6,8-9].

\section{b. Diagnosis of leukorrhea in male patients}

NGU patients present with dysuria, pruritus, burning / burning sensation in the penis, and urethral discharges. Leukorrhea can be purulent, mucoid, or liquid. The amount of leukorrhea in NGU is usually small and only looks like crusts at the meatus or stains on the underwear. Not all male urethritis has symptoms, there are > 40\% asymptomatic cases. Regional lymphadenopathy, constitutional symptoms, or vesicles may complain of urethritis patients with HSV NGU.

The World Health Organization divides the flow of diagnosis and management of urethral discharges based on microscopic (Figure 10) and special laboratory examinations (Figure 11) [22]. Male patients with urethral symptoms should undergo a physical examination for inguinal lymphadenopathy, ulcers, or leucorrhoea that comes out. from the urethra. Palpate gently "milk" over and over towards the shaft of the penis urethra. It is difficult to differentiate between 
gonococcal urethritis and NGU on a clinical basis. In NGU it tends to be mucoid or clear, whereas gonococcal urethritis is more often purulent. Palpation of the scrotum to rule out epididymitis or orchitis.[17] Male urethritis is sometimes accompanied by fever, pain and swelling of the testicles, sore throat, rectal pain, or rectal leukorrhea $[5,7]$

The diagnosis of urethritis is based on clinical findings of mucoid, mucopurulent, or purulent discharges; Gram stain of urethral discharges found two white blood cells (WBC) in the area of one drop of emersion oil; or there is leukocyte esterase on the urinalysis or on the microscopic sediment examination of the first collected urine found $10 \mathrm{WBC}$ per large field of view (TBSA). Diagnosis of NGU can rule out gonorrhea infection based on Gram stain not found in gram-negative or negative diplococci on culture or nucleic acid tests. In men at high risk of infection but do not meet any of the diagnostic criteria for NGU, empiric treatment with drug regimens for chlamydiosis and gonorrhea can be performed. Patients should also undergo a nuleic acid amplification test (NAAT) for chlamydia, gonorrhea, and trichomoniasis. In urethritis, the NAAT test is recommended over culture because of its high sensitivity and specificity [5,7].

Symptoms of recurrent or persistent urethritis can result from drug resistance, poor adherence, or reinfection. The incidence of infection with Trichomonas vaginalis and Mycoplasma genitalium is high, so if there are cases of persistent urethral discharges it should be considered as a condition. examination is difficult to get discharges, or on laboratory examinations the results of nitrite are obtained on the urinalysis, then take a midstream urine specimen and the treatment is directed to urinary tract pathogens. Patients who have risk factors for urethritis should have blood tests for syphilis, HIV and hepatitis B [7].

\section{Management}

Patient education is very essential especially towards young patiennts. Education should include about safe sex, condom use, delay sexual intercourse for at least 7 days after completion of treatment, reduce sun exposure in patients given doxycycline treatment because it can cause photosensitivity, and avoid drinking alcohol in patients given metronidazole treatment. Genital area hygiene education is also important, such as avoiding douching, using fragrance products, and tight synthetic clothing, and educating patients about physiological leukorrhea [5, 7-8, 23]

\section{a. Management of leukorrhea in female patients}

Management of leukorrhea in women is divided into two, namely due to cervicitis and vaginitis. Based on the CDC in 2015, patients who have a high risk (age $<25$ years, have a new sexual partner, have had previous sexual intercourse, or a sexual partner has a history of STIs) for infection with $\mathrm{C}$. trachomatis and $\mathrm{N}$. gonorrhoeae, especially if the investigations cannot be done then the patient can be given presumptive therapy in the form of azithromycin 1 gram single dose orally or doxycycline $100 \mathrm{mg}$ twice a day orally for 7 days. Management of chlamydiosis can be given azithromycin 1 gram single oral dose or doxycycline $100 \mathrm{mg}$ twice daily orally for 7 days. Alternative therapy is erythromycin $500 \mathrm{mg}$ orally 4 times a day for 7 days, or erythromycin ethylsuccinate $800 \mathrm{mg}$ orally 4 times a day for 7 days, or levofloxacin $500 \mathrm{mg}$ orally once daily for 7 days, or ofloxacin $300 \mathrm{mg}$ orally twice daily for 7 days. Pregnant women can be given a single dose of azithromycin 1 gram. Alternative therapy is amoxicillin $500 \mathrm{mg}$ orally three times a day for 7 days, or erythromycin $500 \mathrm{mg}$ orally three times a day, or erythromycin $250 \mathrm{mg}$ orally 4 times a day for 14 days, or erythromycin ethylsuccinate $800 \mathrm{mg} 4$ times a day for 7 days, or erythromycin ethylsuccinate $400 \mathrm{mg} 4$ times a day for 14 days. In ophthalmia neonatorum, patient can be given erythromycin $50 \mathrm{mg} / \mathrm{kg} /$ day orally divided by 4 doses per day for 14 days. Alternative therapy could be azithromycin suspension $20 \mathrm{mg} / \mathrm{kg} /$ day / orally for 3 days. In children $<45 \mathrm{~kg}$ body weight, erythromycin $50 \mathrm{mg} / \mathrm{kg} /$ day, orally divided by 4 doses per day for 14 days, while children weighing $>45 \mathrm{~kg}$ are given azithromycin 1 gram orally as a single dose [23]. 
Leukorrhea caused by gonorrhea is given a single dose of ceftriaxone $250 \mathrm{mg}$ IM plus azithromycin 1 gram orally as a single dose. Alternative therapy is given if ceftriaxone is not available, namely cefixime $400 \mathrm{mg}$ orally as a single dose plus azithromycin 1 gram as a single dose. If the patient is allergic and intolerant to first-generation cephalosporins, give oral gemifloxacin $320 \mathrm{mg}$ plus 2 grams of azithromycin or dual therapy of gentamicin $240 \mathrm{mg}$ IM single dose plus 2 grams of azithromycin. Pregnant women can be given ceftriaxone $250 \mathrm{mg}$ IM as a single dose and azithromycin 1 gram orally as a single dose. Gonococcal conjunctivitis infection is treated with 1 gram of ceftriaxone 1 gram IM as a single dose plus 1 gram oral azithromycin as a single dose. Disseminated gonorrhea is given ceftriaxone therapy 1 gram IM or IV every 24 hours plus azithromycin 1 gram orally as a single dose. Meningitis and endocarditis are given ceftriaxone 1-2 grams IV every 12-24 hours plus azithromycin 1 gram orally as a single dose. Prevention of ophthalmia neonatorum can be given erythromycin eye ointment $0.5 \%$ immediately after the baby is born, while for babies who have detected ophthalmia neonatorum or babies born to mothers suffering from gonorrhea, they are given ceftriaxone $25-50 \mathrm{mg} / \mathrm{kg}$ IV or IM single dose (maximum dose $125 \mathrm{mg}$ ). Sexual partners should be examined within 60 days before symptoms appear and given a single dose of cefixime $400 \mathrm{mg}$ and azithromycin 1 gram. To avoid reinfection it is advisable to patients and their partners not to have sexual intercourse for one week after therapy is finished $[8,23]$.

Recommendations for HBV therapy are metronidazole $500 \mathrm{mg}$ orally twice per day for 7 days, or metronidazole $0.75 \%$ gel one time (5 grams) intravaginally once a day for 5 days, or clindamycin cream $2 \%$ once application (5 grams) intravaginal at bedtime for 7 days. Alternative therapy is tinidazole 2 grams orally once a day for 2 days, or tinidazole 1 gram orally once a day for 5 days, or clindamycin $300 \mathrm{mg}$ orally twice a day for 7 days, or clindamycin ovules 100 $\mathrm{mg}$ intravaginally once a day before going to bed for 3 days. For patients allergic to and intolerant to metronidazole or tinidazole intravaginal clindamycin cream is given. Pregnant women can be given metronidazole 250-500 mg twice a day. Clinical trials have indicated that $\mathrm{BV}$ is not affected by sexual partners, so therapy for sexual partners is not recommended [23].

Trichomoniasis therapy based on the CDC is metronidazole 2 grams orally as a single dose or tinidazole 2 grams orally as a single dose. As an alternative, metronidazole $500 \mathrm{mg}$ orally is given twice per day for 7 days [28]. Patients infected with $\mathrm{T}$. vaginalis are also advised to postpone sexual intercourse until completion of treatment. Examination for other STI diseases including HIV should be performed in patients infected with T. Vaginalis [28]. Recurrent infections or treatment failure are given repeated therapy in the form of metronidazole $500 \mathrm{mg}$ orally twice a day for 7 days. If the treatment fails, can be continued with metronidazole or tinidazole 2 grams orally for 7 days. In pregnant women, metronidazole 2 grams in a single dose can be given.

Short-term topical therapy is said to be effective for the management of uncomplicated VVC, namely clotrimazole cream 1\% 5 grams per day intravaginally for 7-14 days, or clotrimazole cream $2 \% 5$ grams per day intravaginally for 3 days, or miconazole cream $2 \%$ 5 grams intravaginally for 7 days, or miconazole $4 \%$ cream 5 grams per day intravaginally for 3 days, or miconazole $100 \mathrm{mg}$ vaginal suppository once a day for 7 days, or miconazole $200 \mathrm{mg}$ vaginal suppository once a day for 3 days, or miconazole 1,200 $\mathrm{mg}$ vaginal suppository Once a day for 1 day, or thioconazole ointment $80 \mathrm{mg} 6.5 \% 5$ grams intravaginally one application. Prescription intravaginal agents that can be given are butoconazole cream $2 \% 5$ grams single dose intravaginal application, or conazole cream $0.4 \%$ 5 grams intravaginally for 7 days, or conazole cream $0.8 \%$ intravaginally for 3 days, or conazole. $80 \mathrm{mg}$ vaginal suppository once per day for 3 days. Oral therapy that can be given is fluconazole $150 \mathrm{mg}$ orally a single dose [28]. If symptoms persist or recur after 2 months of treatment, a follow-up consultation is needed to determine an accurate diagnosis and treatment regimen. Uncomplicated sexual partners of VVC women should not be given therapy because VVC 
is not sexually transmitted. Uncomplicated VVC treatment in HIV positive patients is the same as HIV negative. As many as $10-20 \%$ complicated VVC is difficult to treat. 7-14 days of topical azole therapy, or $100 \mathrm{mg}, 150 \mathrm{mg}$, or $200 \mathrm{mg}$ oral fluconazole every 3 days are required for 3 total doses. First-line maintenance therapy of oral fluconazole is given 100 $\mathrm{mg}, 150 \mathrm{mg}$, or $200 \mathrm{mg}$ weekly for 6 months. Complicated vulvovaginal candidiasis often occurs in pregnant women. The recommended therapy was topical azole class for 7 days while oral antifungal drugs were not recommended for pregnant women (category C). Severe candidiasis responds well to treatment with topical azole 7-14 days or fluconazole $150 \mathrm{mg}$ two consecutive oral doses (the second dose is given 72 hours after the initial dose) [23].

\section{b. Management of leukorrhea in men}

According to the $2015 \mathrm{CDC}$, the management of urethral discharges in men is divided into gonococcal and non-gonococcal causes [23]. Empiric treatment can be started as soon as the diagnosis is made on microscopic examination to rule out gonococcal infection, waiting for cause-specific test results is unnecessary. Presumptive treatment of NGU with microscopic examination in the form of azithromycin 1 g orally as a single dose or doxycycline $100 \mathrm{mg}$ orally 2 times a day for 7 days. Azithromycin and doxycycline are effective for chlamydial urethritis, whereas urethritis due to $\mathrm{M}$. genitalium responds better to azithromycin. Gonorrhea infection cannot be excluded if Gram stain is not available. For alternative therapy, erythromycin $500 \mathrm{mg}$ is given orally 4 times a day for 7 days, or erythromycin ethylsuccinate $800 \mathrm{mg}$ orally 4 times a day for 7 days, or levofloxacin $500 \mathrm{mg}$ once a day for 7 days, or ofloxacin $300 \mathrm{mg}$ orally 2 times a day for 7 days. Patients are given an effective therapeutic regimen for chlamydiosis and gonorrhea, namely ceftriaxone $250 \mathrm{mg}$ IM plus azithromycin 1 gram orally as a single dose or doxycycline $100 \mathrm{mg}$ orally 2 times a day for 7 days.

Assessment of adherence to previous treatment and re-exposure to disease was carried out in patients with recurrent / persistent leukorrhea symptoms, elevated WBC on microscopic examination, or urinalysis with leukocyte esterase so that treatment was directed to M. genitalium. The recommended therapeutic regimen is 1 gram azithromycin oral single dose given to patients who have not used azithromycin before, or $400 \mathrm{mg}$ moxifloxacin orally per day for 7 days if azithromycin has been used in previous exposure to infection, or 2 grams metronidazole orally single dose for areas affected by many found $\mathrm{T}$. vaginalis $[5,23]$.

\section{Complication}

Leukorrhea can cause serious and life-threatening STI complications in both men and women, although the frequency and severity of complications is generally greater in women.9,17 Complications of NGU in men are rare. A range of $1-2 \%$ of cases can develop epididymitis, 1-2\% conjunctivitis, stricture or urethral stenosis can also occur as a result of post-inflammatory scar formation. The study found a small increase in the incidence of prostatitis and a fourfold risk of developing epididymitis after chlamydial infection, but no reported incidence of infertility. A $1 \%$ range can develop reactive arthritis (Reiter's syndrome) [3].

Women are more often clinically asymptomatic than men. Gonococcal infection and chlamydia in women can cause serious complications, namely ectopic pregnancy and infertility due to tubal occlusion [9]. Research found NGU is more common in women, 10$40 \%$ of cases, and can develop into pelvic inflammatory disease, infertility, and ectopic pregnancy. Babies born to vaginitis mothers have the potential for conjunctivitis, iritis, and pneumonia. Chlamydiosis can also cause lymphogranuloma venereum, a genital ulcer disease that presents as lymphadenitis or lymphangitis and can cause lymphatic obstruction, stricture, or fistula [17]. Untreated chlamydia can increase the risk of infertility and ectopic pregnancy. Infants born to mothers infected with $\mathrm{C}$. trachomatis may develop conjunctivitis and / or pneumonia. Chlamydia trachomatis can infect the eye or is called "trachoma" which causes blindness [18]. Bacterial vaginosis can also predispose to endometritis and salpingitis. 
Mucopurulent cervicitis and BV can simultaneously cause mixed tubal infection [19]. Bacterial vaginosis can also cause abortion in the second trimester of pregnancy, pelvic inflammatory disease, preterm birth, chorioamnionitis, post-gynecological surgery infection, and easier transmission of HIV. Trichomoniasis infection is associated with preterm delivery, premature rupture of membranes, and LBW [9]. A 2004 metaanalysis study by Riggs et al. In 2004 said that as many as $30 \%$ of trichomoniasis patients had a risk of delivering LBW and preterm babies [20]. Vulvovaginal candidiasis in pregnant women can cause Candida infection in neonates and the main cause of septicemia with a morbidity rate of $25 \%$ and a mortality of $25-54 \%$ [9].

\section{Prognosis}

Non-gonococcal urethritis in men resolves spontaneously and does not cause complications in $\mathrm{t}$ improve after the first antibiotic administration, requiring additional therapy, and as many as $80 \%$ of cases recur after treatment. Examination of the wet strip showed persistent infection with trichomoniasis after 60 days of treatment in $12 \%$ of the HIV-negative women and $15 \%$ of the HIV-positive women. Peterman et al. reported recurrent infections increased in women aged 15-39 years, $16.5 \%$ of them found positive cultures at 3 months, 18.5\% 6 months and 12.5\% 9 months after treatment. Recurrent infections were also very high in HIV-positive women, ranging from $18.3 \%$ to $36.9 \%$. Untreated chlamydiosis can last up to 4 years. Early antibiotic therapy in chlamydia provides a favorable prognosis. Infected sexual partners and new sexual partners lead to an increased incidence of recurrent infections. Recurrent infections can lead to scarring in the fallopian tubes and infertility [6].

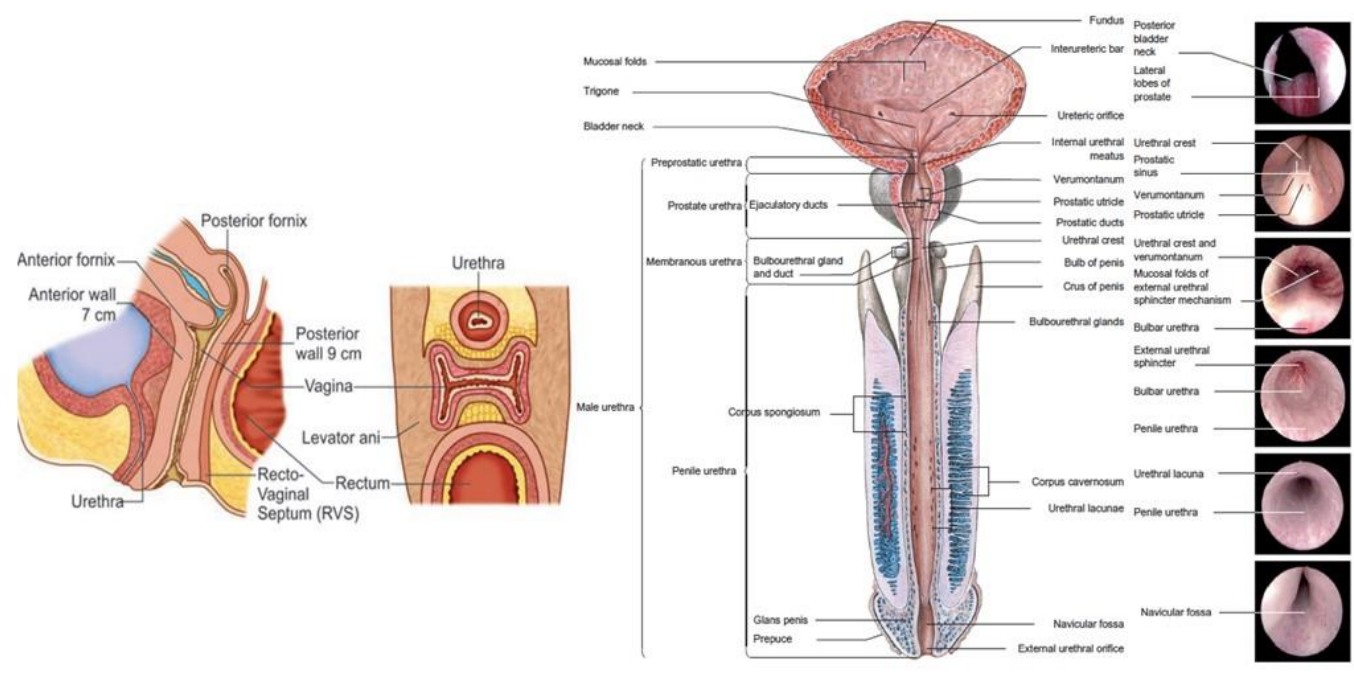

Figure 1. a. Female external and internal genital organ b. Male urethra $[1,12]$

Table 1. Characteristics of vaginal pathological vaginal leukorrhea[8]

\begin{tabular}{llll}
\multirow{2}{*}{ Sign and symptoms } & \multicolumn{3}{c}{ Infection } \\
\cline { 2 - 4 } Discharge & Bacterial vaginosis & Candidiasis & Trichomoniasis \\
\hline Odor & Fishy & White, thick & Few to plenty \\
\hline Itch & Absent & Non-offensive & Offensive \\
\hline
\end{tabular}




\begin{tabular}{llll} 
Other symptoms & $\begin{array}{l}\text { Dyspareunia } \\
\text { Dysuria }\end{array}$ & $\begin{array}{l}\text { Pain } \\
\text { Superficial } \\
\text { dyspareunia }\end{array}$ & \\
\hline Signs & $\begin{array}{l}\text { Discharges covers } \\
\text { vaginal wall and } \\
\text { vestibule }\end{array}$ & $\begin{array}{l}\text { Normal or presence } \\
\text { of }\end{array}$ & $\begin{array}{l}\text { Thick yellowish } \\
\text { discharge }\end{array}$ \\
& No vulvar & Vulvar erythema & Vulvitis \\
& inflammation & Fissure & Vaginitis \\
& & Satelite lessions & Cervisitis \\
& $>4,5$ & $\leq 4,5$ & $>4,5$ \\
\hline Vaginal $\mathrm{pH}$ & & & \\
\hline
\end{tabular}

Table 2. VvC Classification [2]

\begin{tabular}{ll} 
Uncomplicated VVC & Complicated VVC \\
\hline Sporadic atau infrequent; and & Reccurent; or \\
\hline Mild to moderate degree; and & Severe degree; or \\
\hline Common etiology: C. albicans & Non- albicans candidiasis; or \\
\hline Non-immunocompromised women & Uncontrolled Diabetes Melitus, \\
& $\begin{array}{l}\text { paralyzed, immunosuppressed, or } \\
\text { pregnant women }\end{array}$ \\
\hline
\end{tabular}

Adopted from Centers for Disease Control and Prevention (2006)

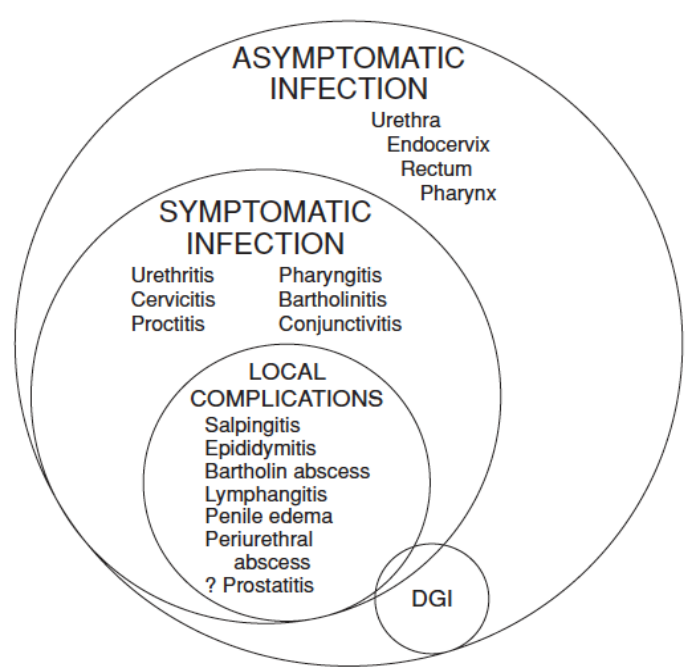

Figure 2. Clinical spectrum of gonococcal infection (DGI; disseminated gonococcal infection) 


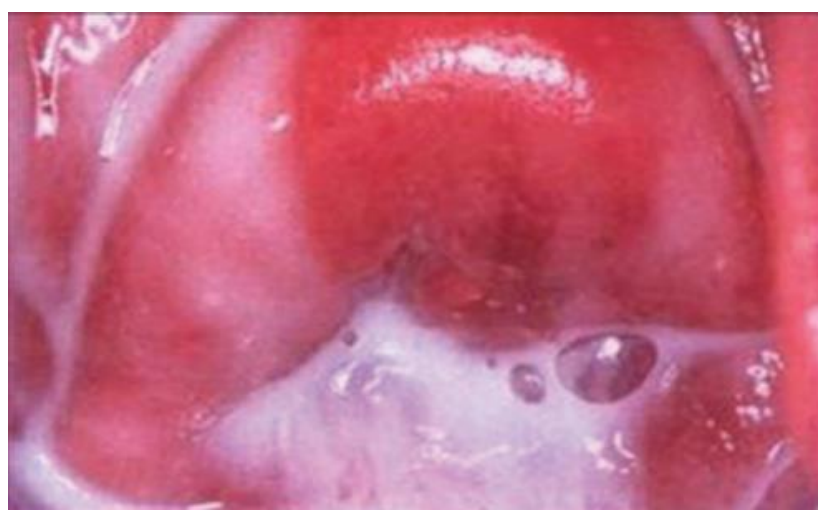

Figure 3. Whitish homogen discharge suggestive of BV. [19]

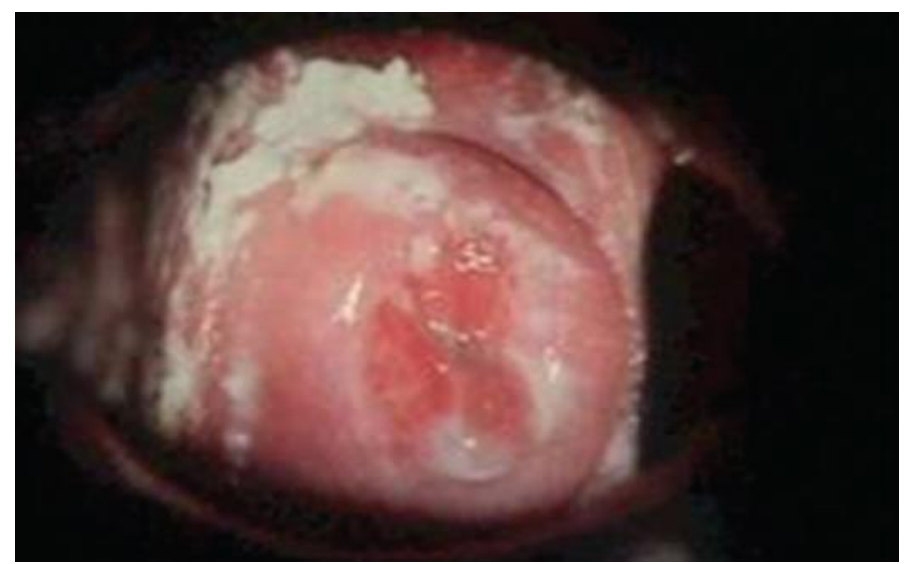

Figure 4. Whitish thick discharge suggestive of candidiasis [19].

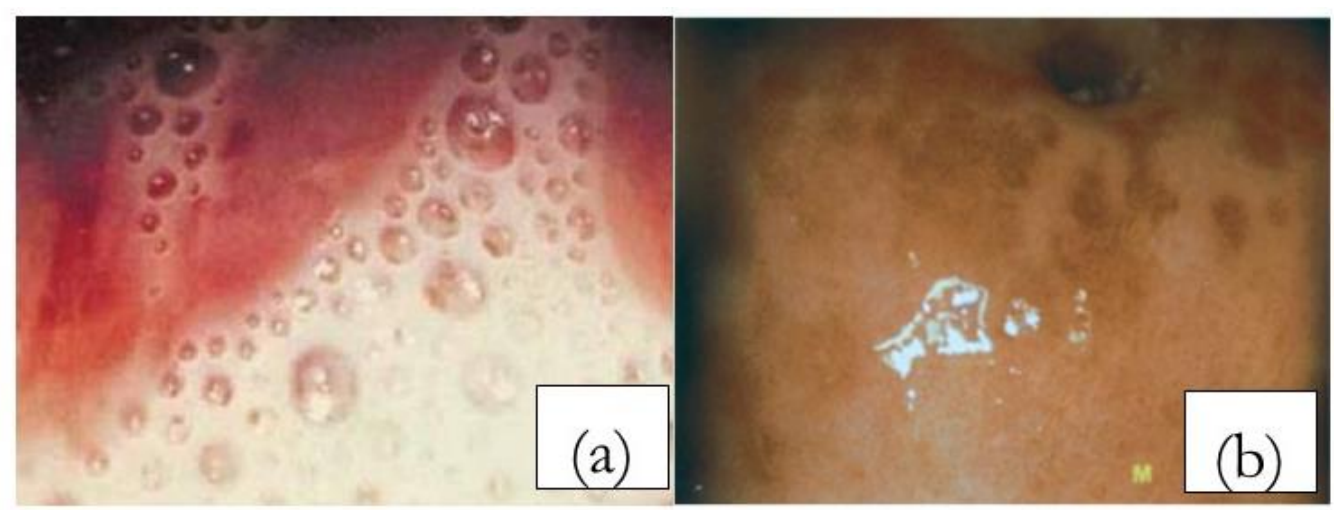

Figure 5. (a) a foamy, whitish color indicating Trichomonas vaginalis infection [15]. (b) Hemorrhagic ptechiae on the vaginal wall are called "strawberry cervix" [20] 


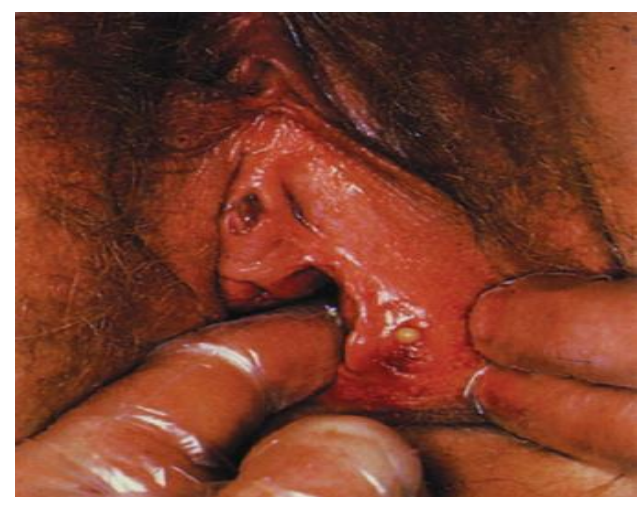

Figure 6. Purulent discharge from the Bartholin glands of a woman with gonococcal Bartholin glands abscess [16].

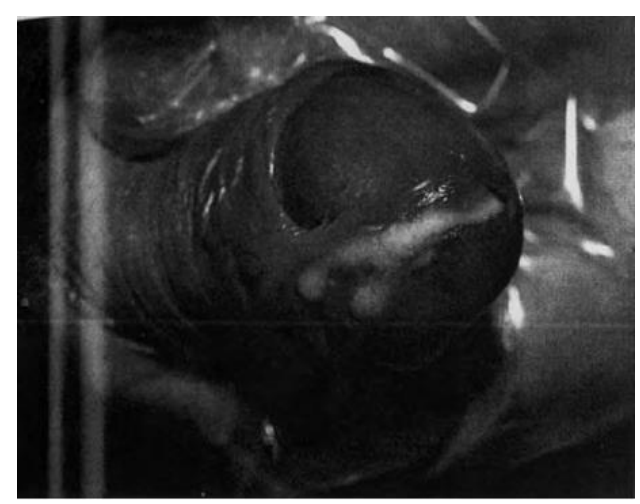

Figure 7. Purulent urethral discharge and penile edema in patient with gonococcal urethritis [16]

Table 3. Wet preparation examination and "whiff" test [6].

\begin{tabular}{ll}
\hline $\begin{array}{l}\text { Without wet preparation } \\
\text { staining }\end{array}$ & $\begin{array}{l}1 \text { drop of } 0.9 \% \mathrm{NaCl} \text { on a glass object mixed with vaginal discharges, cover with a } \\
\text { glass cover without moving it and causing air bubble }\end{array}$ \\
\hline Wet preparation staining & $\begin{array}{l}\text { Mix } 1 \text { drop of } 0.9 \% \mathrm{NaCl} \text { with methylene blue on the slide. Or a mixture of } 0.2 \mathrm{ml} \\
\text { of } 0.5 \% \text { methylene blue and } 1.8 \mathrm{ml} \text { of } 0.9 \% \mathrm{NaCl} \text { in a } 2 \mathrm{ml} \text { syringe. The solution } \\
\text { mixture can be used after a few days with the syringe still closed. }\end{array}$ \\
\hline Whiff test & $\begin{array}{l}\text { Add vaginal discharge with } 1 \text { drop of } 10 \% \mathrm{KOH} \text { solution without covering the glass } \\
\text { cover, causing the smell of amine "fishy odor". }\end{array}$
\end{tabular}

Notes: wet preparation microscopic examination should be performed within 10 minuutes after preparation; if trichomoniasis is suspected, perform examination without wet preparation. 


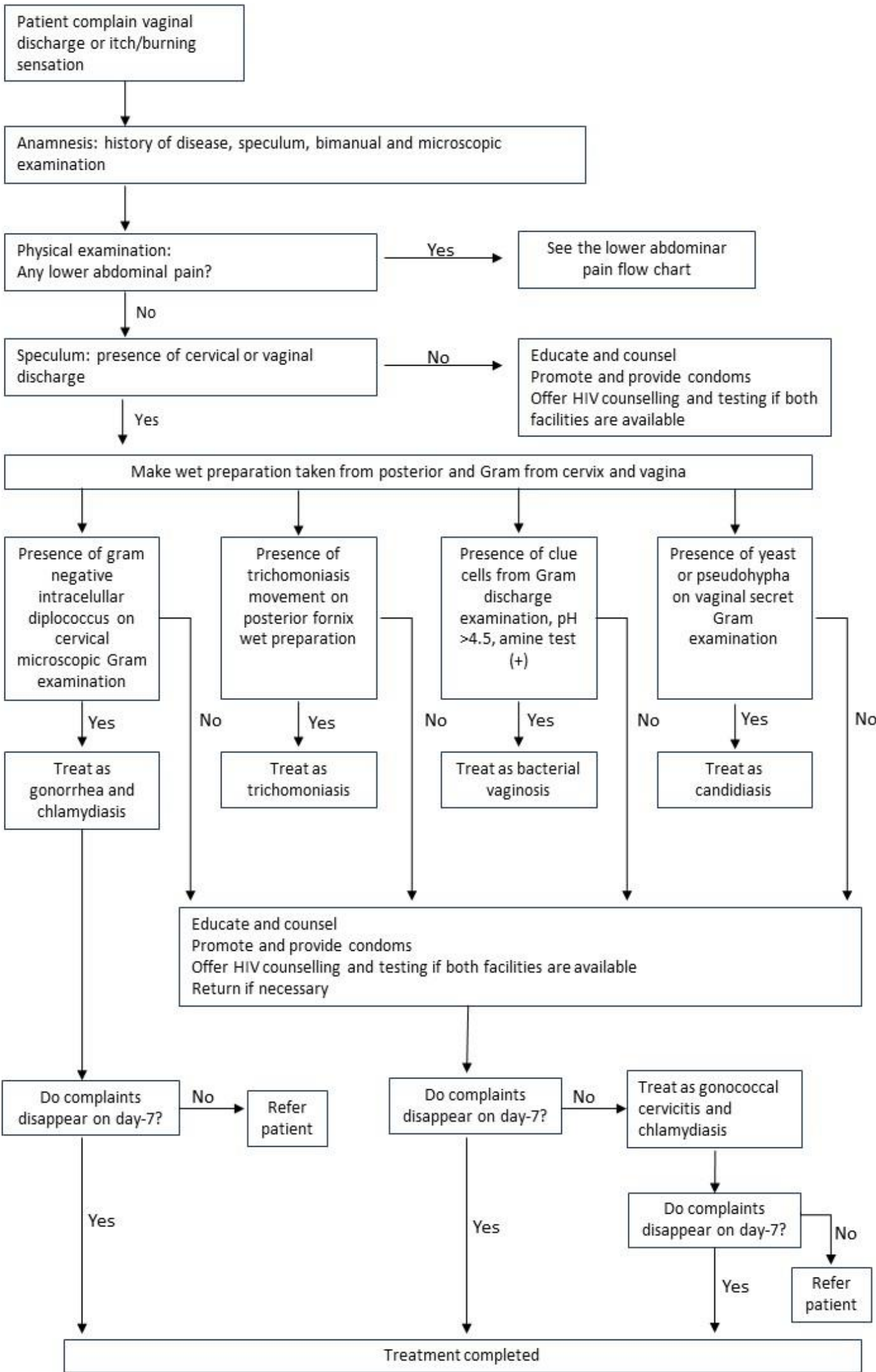

Figure 8. Diagnosis of leukorrhea in female patients with speculum and microscopic examination [22]. 


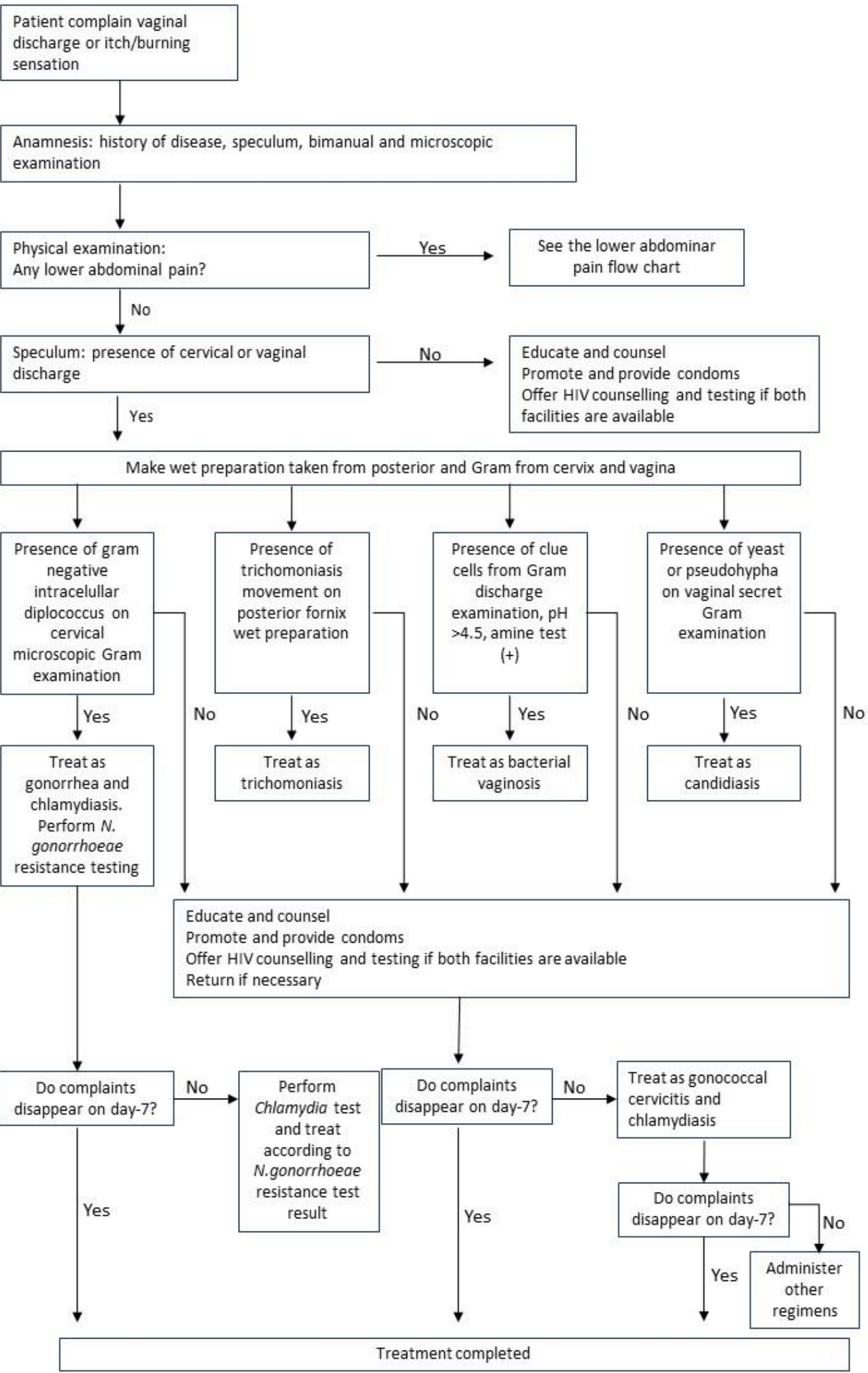

Figure 9. Diagnosis of leukorrhea in female patients with speculum, microscopic, and special laboratory examination [22]. 


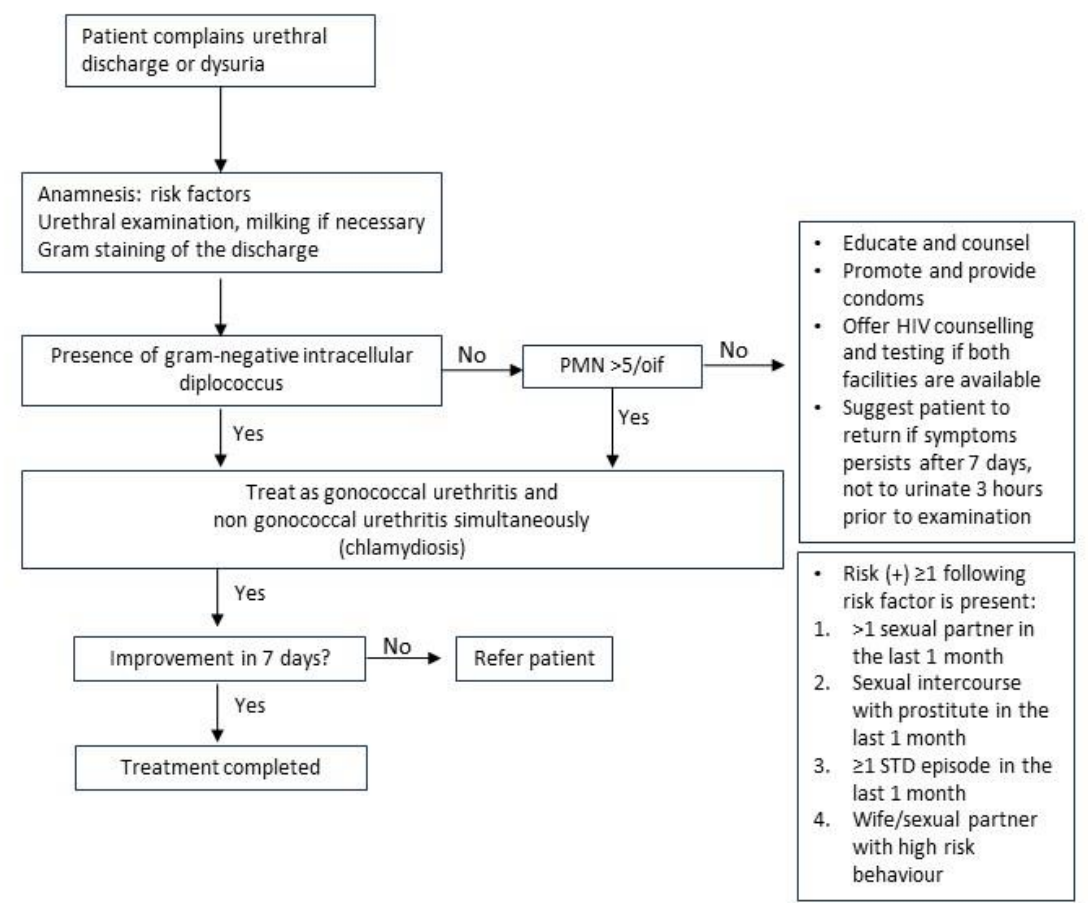

Figure 10. Diagnosis of urethral discharge in male patients with microcopic examination [22].

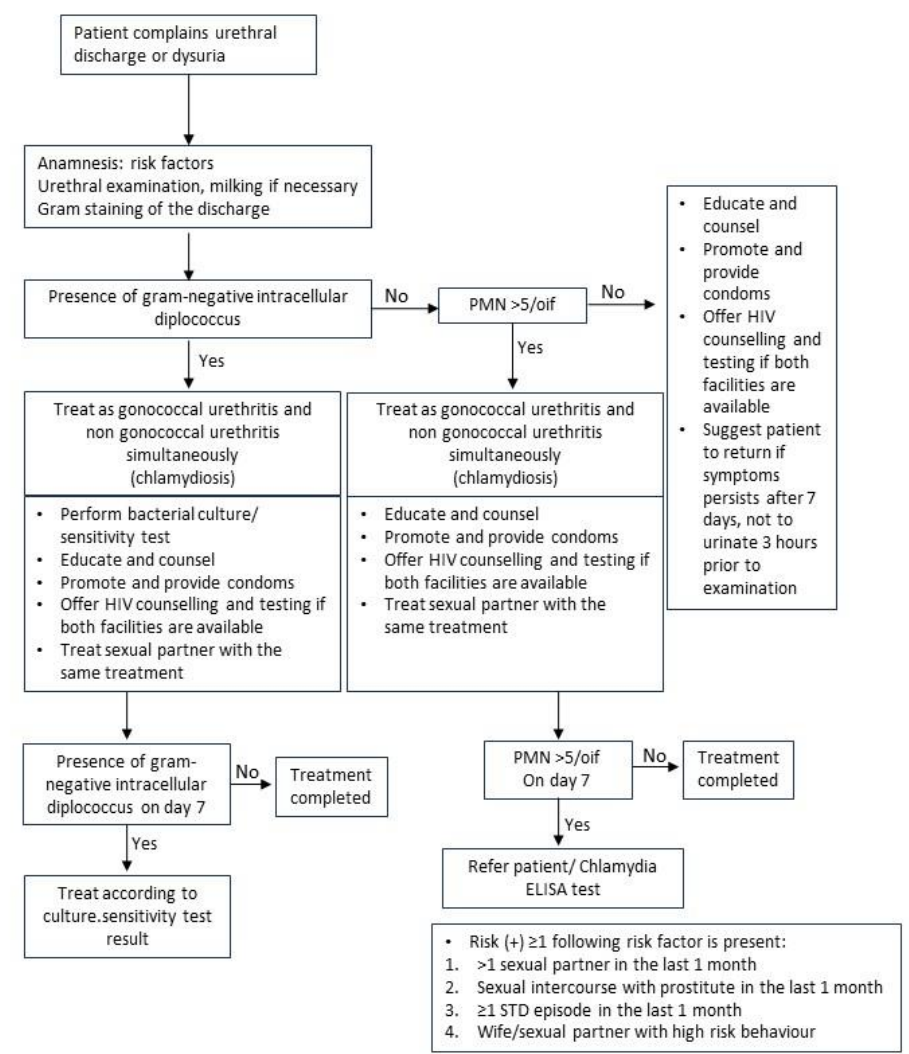

Figure 11. Diagnosis of urethral discharge in male patients with microcopic and special laboratory examination [22]. 


\section{Conclusion}

Leukorrhea, a secretion coming out of the genital organs in excess amounts. In women, leukorrhea is characterized by whitish or yellowish discharge that are usually found at puberty (development of sexual organs). Whereas in men, the body / urethral discharges in a small or large amount indicates an inflammatory response due to any etiological agent and indicates a pathological condition. Hormonal factors have a relationship with the incidence of leukorrhea. An increase in the amount, odor, or color of abnormal vaginal discharges causes STI patients to seek treatment. Symptoms of leukorrhea are generally caused by vaginal infections and rarely due to cervical infections. Complications of STIs can occur in all sexes, found in frequency and severity more in women. The most common complication of gonococcal infection and chlamydia in women is an ectopic pregnancy. Thirty percent of cases of BV resolve without treatment but recurrences are frequent.

\section{Acknowledgment}

There is no conflict of interest.

\section{References}

1. Konar H. Leucorrhea. In: Dutta DC, editor. Textbook of Gynecology. 6th ed. Philadephia: Jaypee Brothers Medical Publishers; 2013. p. 551-579.

2. Rao VL, Mahmood, T. Vaginal discharge. Obst Gyn Reproduct Med. 2019; 30(1): 11-18.

3. Nayak AK, Anoop TV, Sacchidanand S. A clinico-etiological study of urethritis in men attending sexually transmitted disease clinic at a tertiary hospital. Indian $\mathrm{J}$ Transm Dis AIDS 2017; 38(2): 136-141.

4. Bai $R$, Deepthi M, MN D. Analysis of leucorrhoea in tertiary care hospital in rural Bangalore. IJCOG 2018; 2(4): 76-79.

5. Rodrigues J, Galban E, Talhari C, Sardinha JCG, Saraceni V. Effectiveness of syndromic management for male patients with urethral discharge symptoms in Amazonas, Brazil. An
Bras Dermatol 2017; 92(6): 779-84.

6. Frobenius W, Bogdan C. Diagnostic value of vaginal discharge, wet mount and vaginal $\mathrm{pH}$ - an update on the basics of gynecologic infectiology. Geburtshilfe Frauenheilkd 2015; 75: 355-366.

7. Brill JR. Diagnosis and treatment of urethritis in men. Am Fam Physician 2010; 81(7): 873878, 879-880.

8. Hainer BL, Gibson MV. Vaginitis: diagnosis and treatment. Am Fam Physician 2011; 83(7): 807-815.

9. Patel AS, Sheth AN. Vaginitis and Cervisitis. In: Hussen SA, editors. Sexually Transmitted Infections in Adolescence and Young Adulthood a Practical Guide for Clinicians. USA: Springer; 2020. p. 53-68.

10. Venugopal S, Gopalan K, Devi A. Epidemiology and clinico-investigaive study of organisms causing vaginal discharge. Indian $\mathrm{J}$ Sex Transm Dis AIDS 2017; 38(1): 69-75.

11. Ghaddar N, Anastasiadis E, Halimeh $R$, Ghaddar A, Dhar R, et al. Prevalence and antifungal susceptibility of candida albicans causing vaginal discharge among pregnant women in Lebanon. BMC Infectious Diseases 2020; 20(1): 1-9.

12. Clement $\mathrm{P}$, Giuliano F. Anatomy and physiology of genital organs - men. In:Vodusek DB, Boller F, editors. Handbook of Clinical Neurology. 3rd ed; 2015. p. 19-37.

13. Powel AM, Nyirjesy P. New perspectives on the normal vagina and noninfectious causes of discharge. Clin Obstet Gynec 2015; 58(3): 453-463.

14. Ravel J, Gajer P, Abdo Z, Schneider GM, Koenig SSK, et al. Vaginal microbiome of reproductive-age women. Proc Natl Acad Sci U S A 2010, 108(Suppl 1): 4680-7.

15. Hummelen R, Mackklaim JM, Bisanz JE, Hammond JA, McMillan A, et al. Vaginal microbiome and epithelial gene array in postmenopausal women with moderate to severe 
dryness. PLos One 2011; 6(11): e26602.

16. Hook EW, Handsfield HH. Gonococcal Infections in The Adult. In: Holmes KK, Sparling PF, Stamm WE. Piot P, Wasserheit JN, Corey L, et al editors. Sexually Transmitted Diseases. $4^{\text {th }}$ ed. New York: McGraw-Hill; 2008. p. 627-645.

17. Ghosh I, Paul B, Das N, Bandyopadhyay D, Chakrabarti MK. Etiology of vaginal/cervical discharge syndrome: analysis of data from a referal laboratoryin Eastern India. Indian $\mathrm{J}$ Dermatol. 2018; 63(6): 484-489.

18. Stamm WE. Chlamydia tracomatis Infections of the Adult. In: Holmes KK, Sparling PF, Stamm WE. Piot P, Wasserheit JN, Corey L, et al editors. Sexually Transmitted Diseases. $4^{\text {th }}$ ed. New York: McGraw-Hill; 2008. p. 575-593.

19. Hillier S, Marrazo S, Holmes KK. Bacterial Vaginosis. In: Holmes KK, Sparling PF, Stamm WE. Piot P, Wasserheit JN, Corey L, et al editors. Sexually Transmitted Diseases. $4^{\text {th }}$ ed. New York: McGraw-Hill; 2008. p. 737-768.

20. Hobbs MM, Sena AC, Swygard H, Schwebke JR. Trichomonas vaginalis and
Trichomoniasis. In: Holmes KK, Sparling PF, Stamm WE. Piot P, Wasserheit JN, Corey L, et al editors. Sexually Transmitted Diseases. $4^{\text {th }}$ ed. New York: McGraw-Hill; 2008. p. 771-794.

21. Sobel JD. Vulvovaginal Candidiasis. In: Holmes KK, Sparling PF, Stamm WE. Piot P, Wasserheit JN, Corey L, et al editors. Sexually Transmitted Diseases. 4th ed. New York: McGraw-Hill; 2008. p. 823-838.

22. Bagan Alur dan Penatalaksanaan Infeksi menular Seksual. In: Daili SF, Nilasari, Makes WIB, Zubier F, Romawi R, et al editors. Infeksi Menular Seksual. $5^{\text {th }}$ ed. Jakarta: Fakultas Kedokteran Universitas Indonesia; 2017. p. 311-321.

23. Workowski KA, Bolan GA. Sexually transmitted diseases treatment guidelines. In MMWR Recomm Vol. 64 Issue 3. U.S. Department of Health and Human Services Centers for Disease Control and Prevention 2015. p. 51-77.

24. O'connell CM, Ferone ME. Chlamydia trachomatis genital infections. Microb Cell. 2016; 3(9): 390-403. 